Marquette University

e-Publications@Marquette

$9-2000$

\title{
Reversible Dissociation of Thiolate Ligands from Molybdenum in an Enzyme of the Dimethyl Sulfoxide Reductase Family
}

\author{
Robert C. Bray \\ University of Sussex \\ Benjamin Adams \\ University of Sussex \\ Andrew T. Smith \\ University of Sussex \\ Brian Bennett \\ Marquette University, brian.bennett@marquette.edu \\ Susan Bailey \\ CLRC Daresbury Laboratory
}

Follow this and additional works at: https://epublications.marquette.edu/physics_fac

Part of the Physics Commons

\section{Recommended Citation}

Bray, Robert C.; Adams, Benjamin; Smith, Andrew T.; Bennett, Brian; and Bailey, Susan, "Reversible Dissociation of Thiolate Ligands from Molybdenum in an Enzyme of the Dimethyl Sulfoxide Reductase Family" (2000). Physics Faculty Research and Publications. 41.

https://epublications.marquette.edu/physics_fac/41 
Marquette University

e-Publications@Marquette

\title{
Physics Faculty Research and Publications/College of Arts and Sciences
}

This paper is NOT THE PUBLISHED VERSION; but the author's final, peer-reviewed manuscript. The published version may be accessed by following the link in the citation below.

Biochemistry, Vol. 39, No. 37 (1 September 2000): 11258-11269. DOI. This article is (C) American Chemical Society Publications and permission has been granted for this version to appear in $\underline{\mathrm{e}}-$ Publications@Marquette. American Chemical Society Publications does not grant permission for this article to be further copied/distributed or hosted elsewhere without the express permission from American Chemical Society Publications.

\section{Reversible Dissociation of Thiolate Ligands from Molybdenum in an Enzyme of the Dimethyl Sulfoxide Reductase Family}

\author{
Robert C. Bray
}

School of Chemistry, Physics and Environmental Science, University of Sussex, Brighton, BN1 9QJ, U.K. Benjamin Adams

School of Biological Sciences, University of Sussex, Brighton, BN1 9QG, U.K.

Andrew T. Smith

School of Biological Sciences, University of Sussex, Brighton, BN1 9QG, U.K.

Brian Bennett

CLRC Daresbury Laboratory, Warrington, WA4 4AD, U.K.

Susan Bailey

CLRC Daresbury Laboratory, Warrington, WA4 4AD, U.K. 


\section{SUBJECTS:}

Peptides and proteins, Ligands, Crystal structure, Molybdenum, Thiolates

\section{Abstract}

Much is unknown concerning the role of thiolate ligands of molybdenum in molybdopterin enzymes. It has been suggested that thiolate dissociation from molybdenum is part of the catalytic mechanism of bis-molybdopterin enzymes of the dimethyl sulfoxide reductase (DMSOR) family. For DMSOR from Rhodobacter capsulatus, thiolate dissociation has therefore been investigated crystallographically, by UV/visible spectroscopy, and by enzyme assays. When crystallized from sodium citrate, all four thiolates of DMSOR are within bonding distance of $\mathrm{Mo}$, but after extended exposure to $\mathrm{Na}^{+}$-Hepes, a pair of thiolates dissociates, a mixture of structures being indicated after shorter exposures to this buffer. DMSOR is stable in sodium citrate and other buffers but unstable aerobically although not anaerobically in $\mathrm{Na}^{+}$-Hepes. Aerobically in $\mathrm{Na}^{+}$-Hepes, a first-order reaction ( $k=0.032 \mathrm{hr}^{-1}$ at $37^{\circ} \mathrm{C}$ ) leads to loss of activity in the backward but not the forward (dimethyl sulfoxide reduction) assay and loss of absorption at $\lambda>\sim 450 \mathrm{~nm}$. This reaction can be reversed by a cycle of reduction and reoxidation ("redox-cycling"). Slower irreversible loss of activity in the forward assay and cofactor dissociation follow. Spectral analogy with a mono-molybdopterin enzyme supports the conclusion that in the Hepes-modified DMSOR form, only two cofactor dithiolene sulfur atoms are coordinated to molybdenum. Loss of activity provides the first clear evidence that sulfur ligand dissociation is an artifact, not part of the catalytic cycle. Clearly, structural data on DMSOR samples extensively exposed to Hepes is not directly relevant to the native enzyme. The nature of the oxygen ligands detected crystallographically is discussed, as is the specificity of Hepes and the mechanism whereby its effects are achieved. DMSOR forms complexes with $\mathrm{Na}^{+}-\mathrm{Hepes}$ and other buffer ions. For DMSOR crystallized from Hepes, electron density in the substrate binding channel suggests that buffers bind in this site. Like the as-prepared enzyme, the modified form (DMSOR $\left.R_{\bmod } \mathrm{D}\right)$, known to arise on extended aerobic exposure to dimethyl sulfide, is susceptible to a further degradative reaction, although this is not buffer-dependent. It involves loss of absorption at $\lambda>\sim 450 \mathrm{~nm}$ and, presumably, dissociation of thiolate ligands. Evidence is presented that, as a result of $\mathrm{O}_{2}$ damage, DMSOR samples not submitted to redox-cycling may be contaminated with DMSOR $\bmod \mathrm{D}$ and with material absorbing in the region of $400 \mathrm{~nm}$, analogous to the Hepes-modified enzyme. Since the latter lacks absorption at $\lambda>\sim 450 \mathrm{~nm}$, its presence may escape detection.

In molybdenum- and tungsten-containing enzymes that have a bis-molybdopterin structure, the metal atom is coordinated by the four sulfur atoms of two dithiolene units contributed by a pair of molybdopterin (MPT $\left.{ }^{1} ; 1,2\right)$ molecules. These enzymes are widespread in microorganisms, where they catalyze important oxygen atom transfer reactions (3-5). Among them, the dimethyl sulfoxide reductase (DMSOR) molybdenum enzyme family $(\underline{3})$ has attracted particular attention. This includes $(\underline{3,6})$ in addition to DMSOR, the closely related biotin sulfoxide reductase and trimethylamine- $N$-oxide reductase, as well as formate dehydrogenases, respiratory nitrate reductases, and formylmethanofuran dehydrogenase.

DMSOR from photosynthetic bacteria such as Rhodobacter capsulatus and Rhodobacter sphaeroides $(7,8)$ catalyses the final reaction of a respiratory chain with DMSO as the terminal electron acceptor:

$$
\mathrm{DMSO}+2 \mathrm{e}^{-}+2 \mathrm{H}^{+} \leftrightarrow \mathrm{DMS}+\mathrm{H}_{2} \mathrm{O}
$$

Activity is assayed utilizing this reaction in either direction (의). This enzyme contains, unusually, molybdopterin as its only cofactor making it, in principle, particularly amenable to spectroscopic investigations of its molybdenum center. Thus, from a mechanistic point of view, DMSOR from these organisms should be the most 
definitive family member. Nevertheless, despite availability of five crystal structures (10-14), together with much spectroscopic data (e.g., refs 15-19), controversy remains concerning the active center structure and hence the reaction mechanism. Crystallographic structures (10-14) differ from one another in the number of terminal oxygen ligands to the molybdenum atom. Therefore, it has been unclear whether the molybdenum center functions by a mono-oxo/des-oxo catalytic cycle or the alternative di-oxo/mono-oxo cycle. In particular, notwithstanding resonance Raman work $(\underline{16}, 19)$, the existence, nature, and role of a presumed oxygen ligand detected crystallographically in all published DMSOR structures (10-14) and termed 01 by Bailey and coworkers $(\underline{11}, 12)$ remains unclear.

The precise role of the thiolate ligands of molybdenum, not only in bis- but also in mono-MPT enzymes is uncertain. An important unresolved question, potentially concerning all bis-MPT enzymes, is whether all four thiolates remain coordinated to the metal throughout the catalytic cycle. In the crystallographic structures of oxidized, reduced, and DMSO-bound DMSOR as reported by Bailey and co-workers $(\underline{11}, 12)$, all four sulfurs are at normal bonding distances from the metal, implying that the ligands remain coordinated throughout catalysis. A similar conclusion was reached on the basis of resonance Raman spectroscopic studies $(\underline{16,19})$. In contrast, Huber and co-workers $(\underline{14})$ report that in oxidized DMSOR, only two of the four sulfur atoms are within bonding distance. Finally, Rees and co-workers $(\underline{13})$ report one sulfur in the oxidized enzyme to be at the rather long distance of $3.1 \AA$ from the metal, moving to a clearly nonbonding distance of $3.7 \AA$ in the reduced form. They presume such thiolate dissociation to be an integral part of the catalytic cycle. Some further support for dissociation of a sulfur ligand on enzyme reduction has been provided by EXAFS (20). More recently, EXAFS on Paracoccus denitrificans nitrate reductase (21) indicated dissociation of two sulfurs on reduction, with their religation on reoxidation by nitrate. For analogous tungsten enzymes, there is no evidence for asymmetric sulfur coordination in the oxidized enzymes $(5,22,23)$. Nevertheless, on the basis of EPR, it has been suggested that a thiolate may dissociate on reduction to the $W(V)$ state $(\underline{4,5})$. Investigations of conditions that might lead to thiolate ligand dissociation in bis-MPT enzymes are therefore urgently needed.

DMSOR is produced only by organisms growing anaerobically but is isolated and handled aerobically, being apparently stable under such conditions. However, oxygen might have harmful effects on the enzyme, perhaps relevant to thiolate dissociation. Sensitivity to oxygen was underlined by recent studies ( $\underline{9}$ ) of the reaction of the enzyme with DMS. Formation of the initial product $\left[\lambda_{\max }=545\right.$ and $\left.485 \mathrm{~nm} ;(\underline{11})\right]$ takes place at a catalytically competent rate (의) and is followed, aerobically but not anaerobically, by a slow reaction. This leads ( $\underline{9})$ to conversion of the enzyme to a modified form [termed DMSOR mod $_{\text {in }}$ ref 9 and DMSOR $R_{\bmod } D$ here], having $\lambda_{\max }=$ $660 \mathrm{~nm}$. This species, while lacking activity in the backward assay, retains activity in the forward assay and is converted back to the normal enzyme form on submission to a cycle of reduction and reoxidation ("redoxcycling"). Conversion to DMSOR $\bmod D$ may be regarded as a form of oxygen damage to the enzyme, which is fully reversible on exposure to a low redox potential.

We report studies by X-ray crystallography, supported by conventional spectrophotometry and enzyme activity measurements. These reveal a specific DMSOR modification reaction, involving thiolate dissociation and loss of catalytic activity, that is oxygen-dependent and reversible by redox cycling. The work emphasizes the importance, in structural work on bis-MPT enzymes, of avoiding conditions that might lead to formation of oxygen-modified species.

\section{Materials and Methods}

\section{The Purification of DMSOR from R. capsulatus (DMSORap).}

The procedure was generally as outlined earlier (9). R. capsulatus strain $\mathrm{H} 123$ was grown with exclusion of air and photosynthetically in 500-mL medical flat bottles, illuminated with tungsten lamps. Prior to induction of 
DMSOR, growth was at about $25-30{ }^{\circ} \mathrm{C}$, in "RCV" medium (24) supplemented with $30 \mathrm{mM}$ malate as carbon source and $25 \mu \mathrm{g} \mathrm{mL}^{-1}$ kanamycin. Maximum induction of DMSOR was achieved (ㅇ) by transfer to the same medium, without malate and supplemented with $50 \mathrm{mM}$ propionate as a carbon source and $50 \mathrm{mM}$ DMSO. Typically, $10 \mathrm{~L}$ of cells were harvested by centrifugation at $8000 \mathrm{~g}$ for $20 \mathrm{~min}$. The cell pellet was suspended in a minimal volume of $500 \mathrm{mM}$ sucrose in $50 \mathrm{mM}^{2}$ Tris-Cl, 1 mM EDTA, pH 8.0 (buffer A), using a glass homogenizer. To release the periplasm, lysozyme was added (final concentration $0.5 \mathrm{mg} \mathrm{mL}^{-1}$ ), and the cells were incubated at about $20^{\circ} \mathrm{C}$ for $1 \mathrm{~h} \mathrm{(25)}$. Spheroplasts were separated from the periplasm by centrifugation for $30 \mathrm{~min}$, as above. The straw-colored supernatant was the periplasmic fraction, containing most of the DMSOR.

The enzyme was purified by $\left(\mathrm{NH}_{4}\right)_{2} \mathrm{SO}_{4}$ fractionation, at $0-5{ }^{\circ} \mathrm{C}$, precipitating between 60 and $80 \%$ saturation. The $\left(\mathrm{NH}_{4}\right)_{2} \mathrm{SO}_{4}$ precipitate was dissolved in a minimal volume of buffer $\mathrm{A}$ and dialyzed against $15 \%$ saturated $\left(\mathrm{NH}_{4}\right)_{2} \mathrm{SO}_{4}$ in buffer $\mathrm{A}$. The product was fractionated by hydrophobic interaction chromatography on phenyl Sepharose. For 10 - L culture, a $20-\mathrm{mL}$ column equilibrated with $15 \%$ saturated $\left(\mathrm{NH}_{4}\right)_{2} \mathrm{SO}_{4}$ in buffer A was loaded with the dialysate and eluted with a linear gradient of $\left(\mathrm{NH}_{4}\right)_{2} \mathrm{SO}_{4}$, to $0 \%\left(\mathrm{NH}_{4}\right)_{2} \mathrm{SO}_{4}$. Further purification was by ion-exchange chromatography on Q-Sepharose or ResourceQ. DMSOR eluted between 250 and $300 \mathrm{mM} \mathrm{NaCl}$ in buffer A. Partial resolution of DMSOR fractions having slightly different UV/visible spectra was sometimes achieved. For some batches, Fast Flow Phenyl Sepharose (high substitution) rather than the low substitution variety was used in the first chromatographic step, giving better resolution and allowing the ion-exchange step to be omitted. With all procedures, the final product was $>99 \%$ pure as estimated by gel electrophoresis in the presence of SDS. Such samples are referred to as as-prepared DMSOR (DMSORap). DMSOR ap could be converted, by redox-cycling as described below, to DMSOR $\mathrm{R}_{\mathrm{rc}}$.

DMSOR samples (all forms) in buffer A were stored as beads, frozen in liquid nitrogen, at $-80^{\circ} \mathrm{C}$ or below. Care was necessary to avoid slow thawing, since, if the enzyme was repeatedly frozen and thawed, considerable deterioration was observed (increased absorption around $400 \mathrm{~nm}$ ). Enzyme assays in the forward (MV':DMSO) and backward (DMS:PES/DCPIP) directions were according to the standard procedures of Adams et al. (ㅁ) $)$. Enzyme concentrations were estimated from $A_{720 \mathrm{~nm}}$ with $\varepsilon 2 \mathrm{mM}^{-1} \mathrm{~cm}^{-1}$; for dilute samples, precision could be improved by making computed baseline corrections (see below).

\section{Redox-Cycling (Conversion of DMSOR $\mathrm{R}_{\mathrm{ap}}$ to DMSOR $\mathrm{R}_{\mathrm{rc}}$ ).}

The enzyme was caused to undergo a cycle of reduction and reoxidation. The procedure $(9,26$, cf. ref 27$)$ was as for the forward assay, i.e., the reaction was carried out in a spectrophotometer cell with no gas space, anaerobiosis being achieved without the use of nitrogen by the addition of $\mathrm{Na}_{2} \mathrm{~S}_{2} \mathrm{O}_{4}$ from a microsyringe via a fine hole in the stopper. The $\mathrm{MV}$ concentration was $0.3 \mathrm{mM}$, and $\mathrm{Na}_{2} \mathrm{~S}_{2} \mathrm{O}_{4}(\sim 100 \mathrm{mM})$ was added until a stable $A_{600 \mathrm{~nm}} \sim 1$ was achieved, after mixing by inversion with glass beads in the cell. After a few minutes, DMSO (5-10 mM final concentration) was added. On mixing, the color due to MV disappeared at once, and the cell was opened and the sample was gel-filtered aerobically and concentrated by membrane filtration. The same procedure for redox-cycling without DMSO was used, except that the addition of DMSO was omitted. In this case, the blue $\mathrm{MV}^{\bullet}$ disappeared as the sample was removed from the cell.

\section{Preparation of DMSOR $\bmod D$.}

DMSOR $_{r c}$ in buffer $A$ was treated aerobically with DMS at $25{ }^{\circ} \mathrm{C}$ in a tightly sealed spectrophotometer cell until the reaction appeared complete, and then excess reagent was removed by gel-filtration (9).

\section{Spectrophotometric Measurements.}

UV/visible spectra were recorded using a Perkin-Elmer Lambda 16 spectrometer and analyzed using the maker's software and "SigmaPlot" (SPSS Science Software). Deconvolution of spectra (usually 320 to $850 \mathrm{~nm}$ ) was performed with a SigmaPlot routine that optimized their simulation, as the sum of contributions from reference 
spectra and from light-scattering (as $1 /\left[\lambda^{4}\right]$ ) and a horizontal baseline shift. Inclusion of the last two parameters is justified since light-scattering by protein solutions may be increased by small amounts of aggregated material, and since, while the spectrophotometer baseline generally remained horizontal, small shifts in its height did occur. Spectral fits presented correspond to best-fit simulations after correction to the calculated baseline. We used such fitting, first for estimating from observed spectra the relative amounts of the species assumed to be contributing. Three reference spectra were routinely used. ${ }^{2}$ These were experimental spectra of DMSOR $\mathrm{R}_{\mathrm{rc}}$ and of $\mathrm{DMSOR}_{\bmod } \mathrm{D}$ and a synthesized spectrum, "XS400", representing excess absorption in the $400 \mathrm{~nm}$ region and having $\lambda_{\max }=395$ and $\lambda_{\min }=355 \mathrm{~nm}$ superimposed onto a light-scattering background. Subsidiary uses of fitting were to obtain a quantitative estimate of the absolute concentration of one species contributing to the spectrum of a mixture or simply to obtain an estimate of a required baseline correction. Where only small spectral changes are involved and a single reference spectrum only is used in the fitting (but with baseline shifts and light-scattering included), the residual from the fit approximates to the dilution-corrected difference spectrum between the unknown and the reference samples. Such a procedure, which we used for obtaining $\mathrm{pH}$ difference spectra, has the important advantage over conventional ones, in that dilution factors do not need to be known. Difference spectra so obtained may, however, be liable to some slight distortion, e.g., by the false addition or subtraction of light-scattering.

\section{Crystallization and Structure Determination.}

Crystals for the diffraction experiments were obtained at $20-22^{\circ} \mathrm{C}$ using DMSOR ap. A solution of the enzyme in 5 $\mathrm{mM}$ sodium phosphate buffer, $\mathrm{pH} 7.0$, was mixed with an equal volume of crystallization buffer containing 100 $\mathrm{mM} \mathrm{Na}{ }^{+}$-Hepes, $\mathrm{pH} 7.5,2 \mathrm{M}\left(\mathrm{NH}_{4}\right)_{2} \mathrm{SO}_{4}$, and 3-4\% PEG400 and equilibrated by vapor diffusion against the crystallization buffer. These crystallization conditions are different from those reported for previous work (11, 12 ) and yield different crystals. The crystals grow in the space group $P_{212121}$, unit cell dimensions (in $\AA$ ) $a=$ $67.8, b=116.1, c=230.4$, with two molecules in the asymmetric unit. Crystals grew within a few days but were often harvested after a much longer period. Crystals were stored at $20-22{ }^{\circ} \mathrm{C}$ until harvested.

X-ray diffraction data were collected from a number of crystals, under slightly different conditions, either on Station 9.6 of the Synchrotron Radiation Source, CCLRC, Daresbury Laboratory, with X-rays at $\lambda=0.87 \AA$ (datasets I and III) or at the ESRF on BM14 with X-rays at $\lambda=1.0 \AA$ (dataset II). The detector on Station 9.6 was an ADSC CCD system and on BM14 was a 345-mm MAR image plate. Initially, data (dataset I) were collected from a crystal in a sealed capillary at $4{ }^{\circ} \mathrm{C}$. For other datasets, crystals were harvested just prior to data collection into mother liquor containing cryoprotectant for 1-2 min and frozen at $100 \mathrm{~K}$ using an Oxford Cryosystems cryostream. All data were processed using the MOSFLM program (28), and subsequent processing was done using programs from the CCP4 suite (29). Initial phases were obtained by molecular replacement, using dataset I and the published model (12) of the oxidized enzyme. The position of the two molecules in the asymmetric unit was determined using the program AMORE, followed by rigid body refinement with REFMAC. Atomic positions and individual atomic temperature factors were refined for each dataset with the program REFMAC ( $\underline{30})$ using medium NCS restraints and with weak restraints applied to the metal-ligand distances. Cycles of ARP ( $\underline{31}$ ) were used to add solvent atoms. The program $\mathrm{O}(\underline{32})$ was used for inspecting electron density maps and model building. The initial model for refinement of structures using datasets II and III was from a partially refined model from dataset I, and refinement proceeded using the same protocol as that used for dataset I. In all cases, the same reflections ( $5 \%$ of the data) were used for calculation of the free $R$-factor. $\Sigma_{A}$-weighted electron density maps were then calculated using the coefficients $2 \mathrm{~m} F_{\mathrm{o}}-\mathrm{d} F_{\mathrm{c}}, \alpha_{\text {calc }}$ and $\mathrm{m} F_{\mathrm{o}}-\mathrm{d} F_{\mathrm{c}}, \alpha_{\mathrm{calc}}$ (where $F_{\mathrm{o}}$ and $F_{\mathrm{c}}$ represent the observed and calculated structure factors, respectively). After several rounds of refinement and inspection of the model, refinement was terminated with crystallographic $R$-factors and free $R$-factors as given in Table 1 . The two molecules in the asymmetric unit were found to be very similar, both in terms of the polypeptide chain ( $r m s d$ of $0.27 \AA$ for $763 \mathrm{C} \alpha$ ), and in terms of the molybdenum coordination sphere. 
Table 1: Crystallographic Data Collection and Refinement

\begin{tabular}{|c|c|c|c|}
\hline dataset & 1 & II & III \\
\hline approx age of crystals ${ }^{a}$ (months) & 1 & 4 & 2 \\
\hline cryoprotectant & none & $20 \%$ glycerol & $25 \% \mathrm{w} / \mathrm{v}$ sucrose \\
\hline \multicolumn{4}{|c|}{ data collection and processing statistics } \\
\hline resolution $(\AA)$ & 2.4 & 2.0 & 1.9 \\
\hline$R_{\mathrm{sym}}{ }^{b}$ & 0.081 & 0.083 & 0.084 \\
\hline no. of observations & 305979 & 465630 & 367035 \\
\hline no. unique reflections & 59409 & 123010 & 121768 \\
\hline$\%$ complete & 80.4 & 98.1 & 78.2 \\
\hline$\langle I\rangle /\langle\sigma l\rangle \quad$ (last shell) & $7.7(3.8)$ & $5.6(5.1)$ & $5.4(2.8)$ \\
\hline \multicolumn{4}{|l|}{ refinement statistics } \\
\hline resolution $(\AA)$ & $30.0-2.4$ & $30.0-2.0$ & $30.0-1.9$ \\
\hline no. of atoms & 12439 & 13274 & 12748 \\
\hline$R$-factor $(\%)^{c}$ & 17.1 & 19.4 & 17.8 \\
\hline$R_{\text {free }}(\%)$ & 22.3 & 24.1 & 21.6 \\
\hline rmsd $^{d}$ bond lengths & 0.012 & 0.013 & 0.011 \\
\hline rmsd $^{d}$ bond angles (degrees) & 2.4 & 1.9 & 1.9 \\
\hline
\end{tabular}

${ }^{a} \mathrm{DMSOR}_{\mathrm{ap}}$ and $\mathrm{Na}^{+}$-Hepes-containing media were used for growing all the crystals. ${ }^{b} R_{\text {sym }}=\Sigma|l(k)-\langle l\rangle| / \Sigma I(k)$ where $I(k)$ and $\langle l\rangle$ represent the diffraction intensity values of individual measurements and the corresponding mean values. ${ }^{c} R$-factor $=\Sigma\left|F_{\mathrm{o}}-F_{\mathrm{c}}\right| / S F_{\mathrm{o}}$ where $F_{\mathrm{o}}$ and $F_{\mathrm{c}}$ are the observed and calculated structure factor amplitudes. ${ }^{d}$ rmsd $=$ root-mean-square deviation from ideality.

\section{Results}

\section{DMSOR Samples.}

Inspection of UV/visible spectra of DMSOR samples in the literature $(7-9,11,33,34)$ reveals variability not commented on by previous workers. We have developed UV/visible spectral fitting and deconvolution procedures, described in Materials and Methods, to quantify differences in the UV/visible spectra of DMSOR samples. Representative data are summarized in Figure 1 and Table S1 (Supporting Information). A number of points are apparent. With a few exceptions, the spectrum of redox-cycled enzyme (DMSOR rc $_{\text {c }}$ is highly reproducible (e.g., Figure 1a). Freshly prepared $D_{M S O R}$ always shows a resolved peak at about $350 \mathrm{~nm}$ and a trough at about $335 \mathrm{~nm}$, never seen for as-prepared DMSOR (DMSOR ap; see, e.g., Figure 1b). This and the lack of reproducibility in the spectrum of the latter, suggest that $D M S O R_{r c}$ is more likely to represent a single species. We have therefore used DMSOR rc for all experiments, except the crystallization work. Specific activity measurements on $\mathrm{DMSOR}_{\mathrm{rc}}$ samples, expressed as catalytic center activities per $2 \mathrm{e}^{-}$and calculated using enzyme concentrations based on $A_{720}$ values, were comparable to those for DMSOR ap (ㅁ) . Typical values were 28 and $8 \mathrm{~s}^{-}$ ${ }^{1}$ in the forward and backward assays, respectively. The DMSOR ${ }_{a p}$ sample of Figure $1 b$ shows contamination by substantial amounts of DMSOR ${ }_{\text {mod }} D$ (confirmed by a shift in the long-wavelength peak from 723 [( $\underline{9}$ ); measured in Tris-Cl- buffer] to $709 \mathrm{~nm}$ ). However, only a few DMSOR ap samples showed such contamination (Supporting Information, Table S1). DMSOR ap contamination is largely with undefined material or materials responsible for increased absorption in the region of $400 \mathrm{~nm}$, represented by the "XS400" spectrum. Interestingly, the asprepared recombinant DMSOR of Hilton et al. (타) appears from our analysis of the published spectrum to be a mixture of DMSOR $R_{\bmod } \mathrm{D}$ and XS-400-like material. 


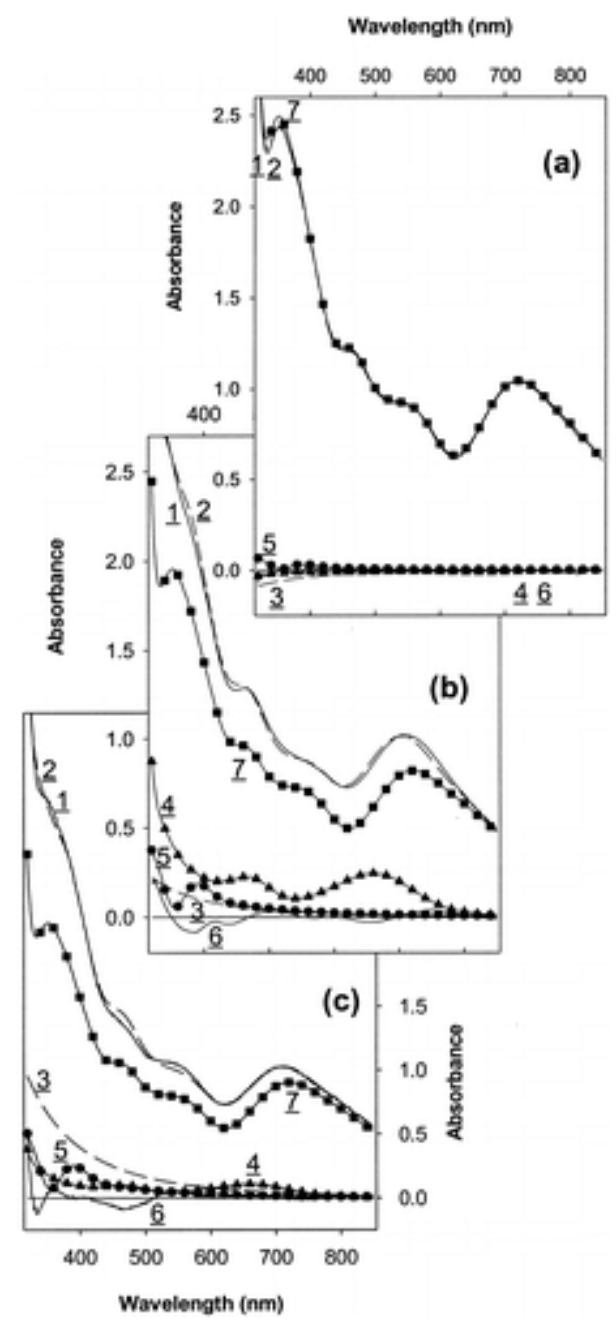

Figure 1 Deconvolution analysis of UV/visible spectra of DMSOR samples. (a) A sample after redox-cycling; (b) the same sample before redox-cycling; this was a somewhat atypical as-prepared DMSOR fraction; (c) $\mathrm{Na}^{+}-$ Hepes-treated DMSOR after redox-cycling. In each case, curve 1 (continuous line) shows the experimental spectrum of the sample examined. This is compared with the appropriately scaled spectrum of reference

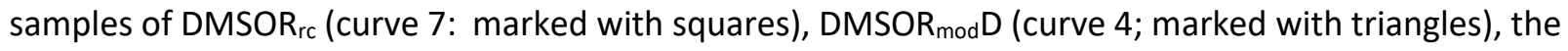
synthesized XS400 spectrum (curve 5: marked with circles; referred to as "XS400", see Materials and Methods) and light-scattering $(1 /[\lambda 4])$ (curve 3: broken line). Curve 2 (broken line) corresponds to a simulation of curve 1, based on the best-fit summation as illustrated, being the sum of curves $3,4,5$, and 7 . Curve 6 (continuous line)is the residual from the fit (i.e., curve 1 minus curve 2).

It was noteworthy that although we routinely used DMSO, redox-cycling could also be performed successfully without any added oxygen donor. Redox-cycling without DMSO has previously been achieved (16) using ferricyanide as the oxidant.

\section{Effect of the Medium on the Molybdenum Center in the Crystallographically Determined} Structure: Time-Dependent Effects of Hepes Buffer.

Crystallization of DMSOR and related enzymes for structure determination has previously been reported from sodium citrate $(\underline{11}, 12)$, cacodylate $(\underline{10}), \mathrm{Na}^{+}-\mathrm{Mes}(\underline{14})$, or $\mathrm{Na}^{+}$-Hepes $(\underline{13})$ buffers. Three new structures of $\mathrm{DMSOR}_{\mathrm{ap}}$ have been refined using data obtained from crystals grown with new crystallization conditions, in all cases in the presence of Hepes. The positions of atoms in the protein backbone and in the MGD cofactors superimpose, within experimental error, when these models are compared (Table 2) with one another and with 
our published model (12). However, there are significant differences in the position of the molybdenum ion and hence in its coordination sphere (Table 2). Our first structure from crystallization conditions with Hepes buffer (structure I) appeared very similar to the structure of DMSOR crystallized using citrate [(르), Figure 2a] within the limited resolution $(2.4 \AA)$ of the data. The molybdenum site was initially refined to be the same as this, with all four thiolates within bonding distance of the metal and with three oxygen ligands, $\mathrm{\gamma}$ of Ser 147, 01 , and $\mathrm{O} 2$ (Figure 2a). Peaks were observed in difference density maps if either $\mathrm{O} 1$ ( $4.5 \sigma$ and $6.0 \sigma$ peaks $^{3}$ in molecules $\mathrm{A}$ and $\mathrm{B}$, respectively) or $\mathrm{O} 2$ ( $5.0 \sigma$ and $5.5 \sigma$ peaks) were omitted from the refinement, and these atoms refined to reasonable occupancies. However, spectroscopic data (e.g., refs 16, 17, and 20) do not support two oxo ligands. The evidence presented by the structures described below demonstrates that under certain conditions the molybdenum moves within the structure to a position that is very close to the suggested position of 01 (see Discussion).

(a)

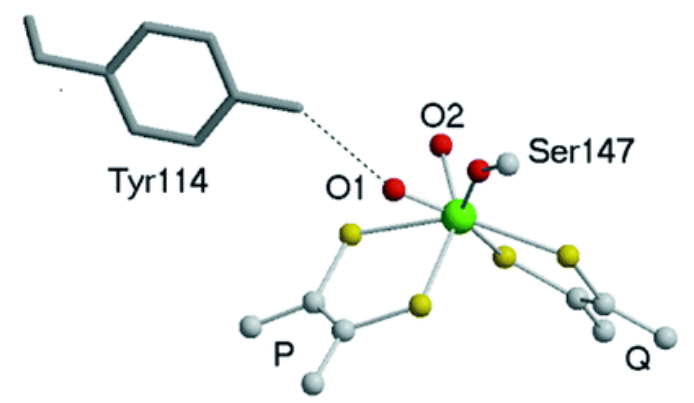

(b)

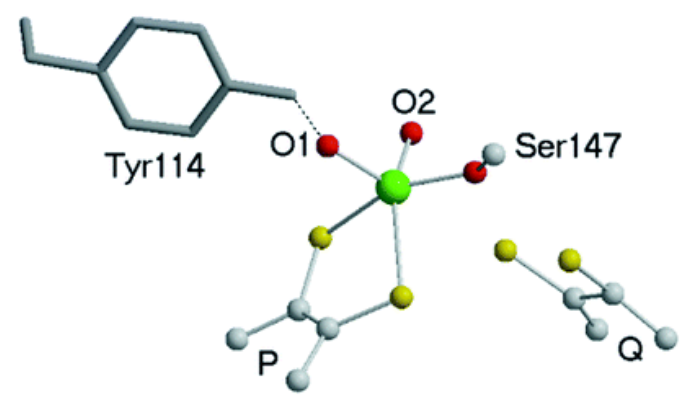

Figure 2 Structure around molybdenum in DMSOR. (a) Crystallized from citrate buffer (12) and (b) after extensive exposure to Hepes, structure II (present work), showing maximum thiolate ligand dissociation. P and Q represent the two MGD molecules. This figure and Figure 3 were prepared using the programs MOLSCRIPT ( $\underline{44})$ and RASTER3D (모).

Table 2: Metal-Ligand Distances from the Crystallographically derived Structures ${ }^{a}$

\begin{tabular}{|l|l|l|l|l|}
\hline & distances in $\AA$ (A, B) & & & \\
\hline structure (dataset) & $\mathrm{I}$ & $\mathrm{II}$ & $\mathrm{II}^{b}$ (Mo position 1) & $\mathrm{II}^{b}$ (Mo position 2) \\
\hline Mo-MGD-P S1' distance & $2.5,2.5$ & $2.6,2.6$ & $2.5,2.5$ & $2.6,2.7$ \\
\hline Mo-MGD-P S2' distance & $2.6,2.5$ & $2.4,2.4$ & $2.7,2.7$ & $2.2,2.2$ \\
\hline Mo-MGD-Q S1' distance & $2.5,2.5$ & $3.4,3.4$ & $2.3,2.3$ & $3.7,3.8$ \\
\hline Mo-MGD-Q S2' distance & $2.6,2.5$ & $4.0,4.1$ & $2.7,2.6$ & $4.0,4.2$ \\
\hline Mo-Ser 147 Op distance & $2.0,1.9$ & $1.9,1.9$ & $1.9,1.9$ & $1.9,2.1$ \\
\hline Mo-O1 distance & $1.8,1.8$ & $1.9,2.0$ & not detected & not detected \\
\hline Mo-O2 distance & $1.8,1.8$ & $2.0,2.0$ & $2.0,1.9$ & $1.8,1.8$ \\
\hline molybdenum movement & $0.1,0.1$ & $1.4,1.3$ & $0.2,0.2$ & $1.5,1.7$ \\
\hline $\begin{array}{l}\text { rmsd of 763 Ca of the poly } \\
\text { peptide }\end{array}$ & $0.15,0.16$ & $0.28,0.35$ & $0.29,0.30$ & \\
\hline
\end{tabular}


chain from the reference $s$

tructure

${ }^{a}$ These are given for the two molecules, $A$ and $B$ in the asymmetric unit. The movement of the molybdenum atom is measured using the $1.82 \AA \mathrm{DMSOR}_{\text {ap }}$ structure $(\underline{12})$ as reference. ${ }^{b}$ Mo-ligand distances are given for comparison with previous structures only. These distances will be less reliable than for structures I and II, as only one position was refined for each ligand atom, and two alternative Mo positions were refined.

Subsequently, data were collected to 2.0 - $\AA$ resolution from frozen crystals, using glycerol as cryoprotectant (structure II, Figure $2 \mathrm{~b}$ ). The structure refined against these data appeared to be more like the reported structure of Huber and co-workers (14). In particular, the molybdenum has moved by approximately $1.4 \AA$ away from the Q-MGD [nomenclature of ref 13], and only the two thiolates of the P-MGD remain within bonding distance of the molybdenum. Ser147 is also a ligand to the molybdenum, but assigning the remaining ligands was more difficult. Three peaks were observed around the molybdenum in the difference electron density maps. Two peaks in similar positions to $\mathrm{O} 1$ and $\mathrm{O} 2$, (peak heights $6.8 \sigma$ and $4.6 \sigma$ in molecule $A, 6.8 \sigma$ and $5.8 \sigma$ in molecule B) were assigned as oxygens, and both refine to a distance of 1.9-2.0 $\AA$ from the molybdenum. These oxygens are hydrogen-bonded to the $\mathrm{OH}$ of Tyr 114 and $\mathrm{N} \varepsilon 1$ of Trp 116 and in equivalent positions to Oa and Oe, respectively, in the structure of Huber and co-workers (14). A third peak (height $7.5 \sigma$ and $9.5 \sigma$ in molecules $A$ and $B$ ) in the difference density maps could be interpreted as a third oxygen, giving a total of six ligands in octahedral geometry around the metal. However, it is rather close to the thiolates of the Q-MGD and may alternatively be interpreted as residual electron density due to a proportion (approximately 20\%) of the molybdenum not moving.

Fearing that the glycerol was causing the movement of the molybdenum and associated changes in the coordination sphere of the metal, we collected data from a frozen crystal, again using Hepes buffer but using sucrose as cryoprotectant. In this case, we saw a mixture of the two previous structures with approximately 55\% of the molecules in the crystal having the molybdenum in one position and $45 \%$ having the molybdenum in the alternative position. The resolution of the data are probably insufficient to give an accurate model of the ligand sphere around the metal in the presence of two alternative positions of such a heavy scatterer as a molybdenum. However, we were able to refine single positions for $\mathrm{O} 2$ and Ser 147, with reasonable metal ligand distances to both molybdenum positions (stucture III, Table 2). There was no evidence for 01 . This structure suggested that it was not the glycerol causing the molybdenum movement, and other possibilities were considered, including the effect of temperature and of the buffer. The observation that variable degrees of molybdenum movement had occurred, which could be roughly correlated with the age of the crystals (Table 1), suggested a slow time-dependent process.

\section{Comparison of the Position of Molybdenum in Structures of DMSOR.}

Figure 3 shows a superimposition of the active site of structures I and II presented in this paper and three published structures of the oxidized enzyme (12-14). It is clear that there are two well-defined alternative positions for the molybdenum atom, while the majority of other atoms in the vicinity of the metal do not move. There are obvious differences in the sulfur ligation to the molybdenum in the two positions. In one position, all four dithiolene sulfurs are within bonding distance of the molybdenum. In the other position, the molybdenum is still within bonding distance of the dithiolene sulfurs of one cofactor but at least $3.4 \AA$ from the thiolates of the other cofactor. It is also possible that there are changes in the oxygen ligation to the molybdenum, although Oy of Ser 147 remains as a ligand in all models. O2, the oxygen ligand hydrogen-bonded to Trp 116, is present in all oxidized structures of DMSOR from $R$. capsulatus, although it is absent from the published structure of DMSOR from $R$. sphaeroides (13). In the enzyme with DMSO complexed to the metal and the dithionite-reduced enzyme $[(\underline{11}, 12)$; not shown] all four dithiolene sulfurs are within bonding distance of the metal. These latter 
structures, in conjunction with the present ones, strongly suggest that $\mathrm{O} 2$ is the oxygen transferred during enzyme catalysis. The function of $\mathrm{O} 1$ is more difficult to explain, if indeed it is not an artifact (see Discussion).

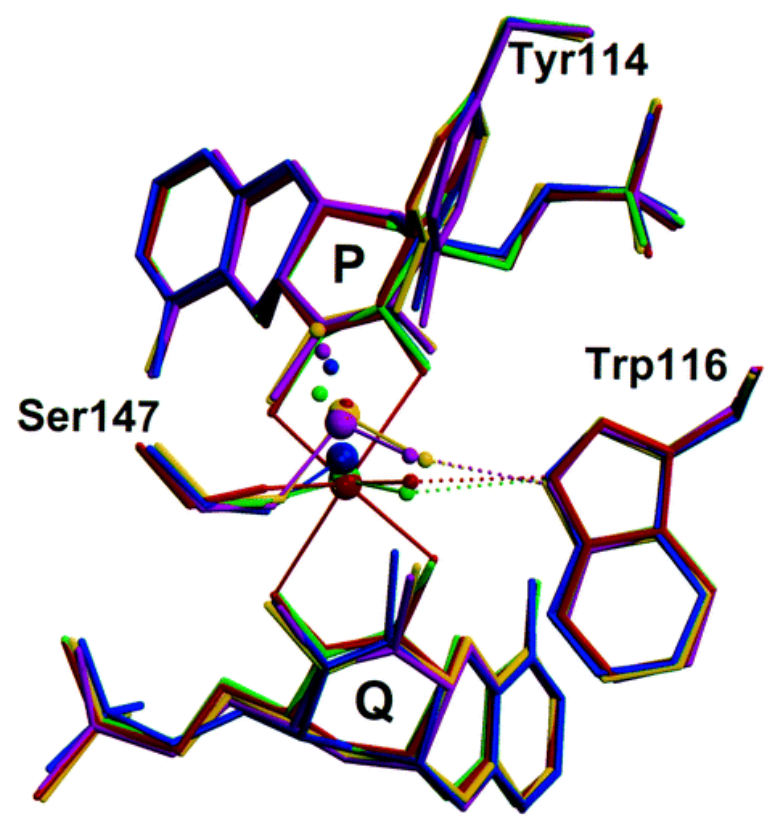

Figure 3 Superimposition of structures of oxidized DMSOR. The structure of the enzyme when crystallized from citrate [(12), red] and structure I (present work, green) have the molybdenum coordinated by four thiolate ligands. Structure II (present work, yellow) and the structure of Huber and co-workers [(14), magenta)] are coordinated by only two thiolate ligands (from P-MGD) while the structure of DMSOR from $R$. sphaeroides $[(\underline{13})$ blue] appears to have the molybdenum halfway between the two positions. 01 (hydrogen bonded to Tyr 114) appears to move with the molybdenum, whereas the movement of $\mathrm{O} 2$ (not seen for the $R$.

sphaeriodes structure; hydrogen-bonded to Trp 116) is less. The molybdenum in our reported structures of dithionite-reduced (12) and DMSO-complexed (11) enzymes (not shown) is coordinated by four thiolate ligands and superimposes almost exactly on the molybdenum of the enzyme crystallized from citrate.

\section{Specific Effects of $\mathrm{Na}^{+}$-Hepes Buffer on the Stability of DMSOR.}

To seek to understand the effects of $\mathrm{Na}^{+}$-Hepes in the crystallographic work, we carried out a series of experiments in which the stability of DMSOR in different buffers was assessed by enzyme activity measurements and by changes of UV/visible absorption spectrum. Incubation of the enzyme for 2 days at $37^{\circ} \mathrm{C}$ in different media revealed (Table 3 ) a dramatically diminished stability in $\mathrm{Na}^{+}$-Hepes in comparison with that in Tris- $\mathrm{Cl}^{-}$, sodium citrate, or $\mathrm{Na}^{+}$-Ches. In buffers other than Hepes, the spectrum was essentially unaffected by this incubation, as shown by estimations of the $D_{M M S O R}$ concentrations before and after incubation from spectral deconvolution (see Materials and Methods). In contrast, in $\mathrm{Na}^{+}$-Hepes the long-wavelength features of the spectrum were greatly diminished by the incubation, leaving a relatively featureless spectrum with a pronounced shoulder at about $400 \mathrm{~nm}$. Deconvolution indicated loss of the greater part of the DMSOR $\mathrm{rc}_{\mathrm{rc}}$ with substantial conversion to material with an XS400-like spectrum. Activity in the forward assay was essentially unchanged in all samples. In contrast, uniquely for the $\mathrm{Na}^{+}$-Hepes samples in the backward assay, activity was diminished by $80 \%$ or more. Results indistinguishable from those in Table 3, experiment 1, were obtained when EDTA was omitted (data not shown), so that inactivation in the presence of $\mathrm{Na}^{+}$-Hepes is not dependent on trace metals. However, the backward assay activity loss was essentially eliminated by anaerobiosis (Table 3, experiments $2 \mathrm{a}$ and $\mathrm{b}$ ). Thus, inactivation in the presence of $\mathrm{Na}^{+}$-Hepes is oxygen-dependent.

Table 3: Effect on DMSOR of Aerobic Incubation for $45 \mathrm{~h}$ at $37^{\circ} \mathrm{C}$ in Different Buffers ${ }^{a}$ 


\begin{tabular}{|c|c|c|c|c|c|}
\hline & expt no. & sodium citrate & Tris-Cl- $^{-}$ & $\mathrm{Na}^{+}$-Ches & $\mathrm{Na}^{+}$-Hepes \\
\hline before: DMSOR $_{\mathrm{rc}}$ conc (from spectrum ${ }^{b}$ ) & 1 & $(100)$ & 95 & & 101 \\
\hline after: $\mathrm{DMSOR}_{\mathrm{rc}}$ conc (from spectrum ${ }^{b}$ ) & 1 & 104 & 89 & & $27^{c}$ \\
\hline after: activity (forward assay) ${ }^{d}$ & 1 & $(100) \pm 9$ & $93 \pm 6$ & & $95 \pm 6$ \\
\hline after: activity (backward assay) ${ }^{d}$ & 1 & $(100) \pm 12$ & $81 \pm 9$ & & $16 \pm 4$ \\
\hline after: activity (backward assay) ${ }^{d}$ & $2 a$ & & $96 \pm 5$ & $104 \pm 12$ & $10 \pm 4$ \\
\hline after: activity (backward assay) ${ }^{d}$ & $2 b$ (anaer.) & & $99 \pm 10$ & $101 \pm 10$ & $67 \pm 8$ \\
\hline
\end{tabular}

${ }^{a}$ The enzyme was $20 \mu \mathrm{M}$ in experiment 1 and $7 \mu \mathrm{M}$ in experiments $2 \mathrm{a}$ and $2 \mathrm{~b}$. Experiments 1 and $2 \mathrm{a}$ were carried out aerobically. For experiment $2 \mathrm{~b}$, samples were made anaerobic in a glovebox operating at $\sim 5 \mathrm{ppm}$ oxygen. Buffers and $\mathrm{pH}$ values were as follows. In experiment 1, $\mathrm{Tris}^{-\mathrm{Cl}^{-}}$was $20 \mathrm{mM}, \mathrm{pH} 7.5$, sodium citrate was $85 \mathrm{mM}, \mathrm{pH}$ 5.0, and $\mathrm{Na}^{+}$-Hepes was $85 \mathrm{mM}, \mathrm{pH} 7.5$. In experiments $2 \mathrm{a}$ and $2 \mathrm{~b}$, all samples were at $\mathrm{pH} 8.2$, with Tris- $\mathrm{Cl}^{-}$at $50 \mathrm{mM}$ and $\mathrm{Na}^{+}$-Ches and $\mathrm{Na}^{+}$-Hepes at $80 \mathrm{mM}$, with $10 \mathrm{mM}$ Tris-Cl also present for the last two samples. In all experiments, $1 \mathrm{mM}$ EDTA was also present. Forward and backward assays were performed as described in Materials and Methods. ${ }^{b}$ For experiment 1, UV/visible spectra were recorded before and after incubation. Values are calculated concentrations of $\mathrm{DMSOR}_{\mathrm{rc}}$ expressed relative to the value in sodium citrate before incubation, taken as 100. They were obtained as described in Materials and Methods from deconvolution of the spectra. Indicated relative amounts (as in Supporting Information, Table S1) of DMSOR mod $\mathrm{D}$ and of the XS400 spectrum were generally small (within the range \pm 0.06 ). The one exception was for the sample in $\mathrm{Na}^{+}-$ Hepes after incubation, for which much higher contributions from the XS400 spectrum were indicated. ${ }^{c}$ The indicated relative amount of the XS400 spectrum (as in Supporting Information, Table S1) was 0.76. ${ }^{d}$ In experiment 1 , values given correspond to activities relative to the value in sodium citrate after incubation, taken as 100. Calculated specific activity values for the latter were similar to those of typical unincubated $D_{M S O R}$ samples. In experiments $2 a$ and $2 b$, activities are expressed relative to those measured in unincubated controls, after making small corrections for evaporation.

During preparative-scale inactivation in $\mathrm{Na}^{+}$-Hepes, there was progressive disappearance of all the longwavelength absorption features, with more subtle changes in the $400-450 \mathrm{~nm}$ region (Figure 4a). Figure 4, panels $\mathrm{b}$ and $\mathrm{c}$, show detailed kinetic analysis of these data, supplemented by results of activity assays in both directions. DMSOR $\mathrm{rc}_{\mathrm{rc}}$ concentrations from spectral fitting in the long-wavelength region only, agree (Figure 4b) with data from the backward assay in indicating that the normal enzyme form disappears via a first-order reaction with a rate constant of about $0.03 \mathrm{hr}^{-1}$. This is supported by analysis of relative absorbance changes at 720, 630, and $352 \mathrm{~nm}$ (Figure 4c). However, closer examination reveals some complications. Whereas, the curve fitted to the activity data (Figure $4 b$, curve 1 ) extrapolates within experimental error to zero activity, the $\mathrm{DMSOR}_{\mathrm{rc}}$ concentration plot extrapolates not to zero but to a statistically significant apparent residual content of this species. Close inspection shows, however, an associated small shift of the 720-nm peak toward shorter wavelengths as the reaction proceeds. ${ }^{4}$ More dramatically, analysis of relative absorbances at $430 \mathrm{~nm}$ (Figure 4c) provides clear indications of a secondary phase in the reaction following the primary phase. Furthermore, activities in the forward assay (at zero and at longest reaction times only) show a small but significant decrease, not obviously associated with the primary reaction phase. 


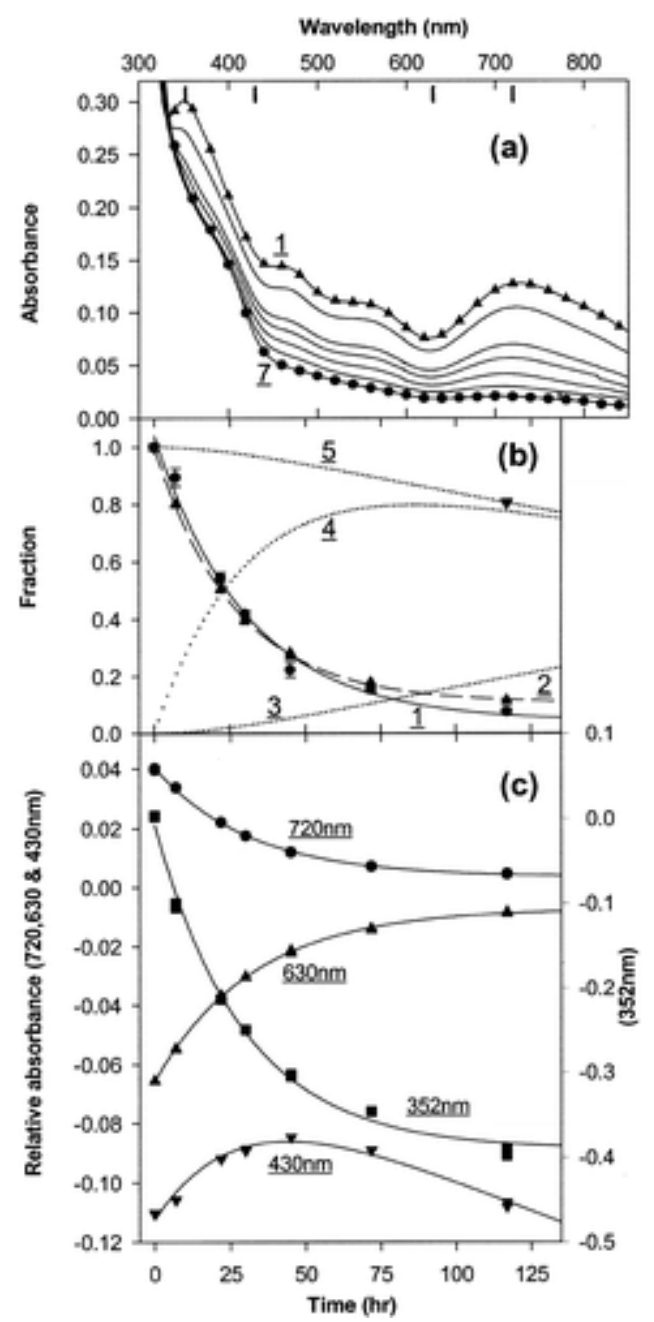

Figure 4 Kinetics of aerobic DMSOR modification at $37^{\circ} \mathrm{C}$ in the presence of $\mathrm{Na}^{+}$-Hepes. Panel a: UV/visible spectra recorded at intervals during the reaction. Panels $b$ and $c$ show secondary plots derived from these data, together with enzyme activity data. In panel a, curves 1-7 correspond to spectra at the following reaction times: $0,7.0,21.9,30.0,45.0,71.7$, and $117.0 \mathrm{~h}$. Triangle and circle markers, respectively, distinguish the time 0 and $117 \mathrm{~h}$ curves. The experiment was carried out starting with $65 \mu \mathrm{M} \mathrm{DMSOR}_{\mathrm{rc}}$ in $100 \mathrm{mM} \mathrm{Na}{ }^{+}-\mathrm{Hepes}, 45 \mathrm{mM}$ Tris$\mathrm{Cl}^{-}$, and $1 \mathrm{mM}$ EDTA, $\mathrm{pH}$ 7.5. Small baseline corrections have been applied to the spectra. In panel $b$, the fraction remaining of activity in the backward assay (circles; with SD from triplicate assays) and of $\mathrm{DMSOR}_{\mathrm{rc}}$ concentrations as estimated from fits to the spectrum over the range 460-815 nm (upright triangles; points in duplicate) are plotted against time. The fraction of activity remaining in the forward assay is shown as inverted triangles. Curves 1 and 2 (continuous and dashed lines) correspond respectively to first-order decay with rate constants of $0.032 \pm 0.005 \mathrm{hr}^{-1}$ and $0.037 \pm 0.001 \mathrm{hr}^{-1}$ and with limiting fractions remaining of $0.04 \pm$ 0.05 and $0.11 \pm 0.00$. Curves 3,4 , and 5 are theoretical plots respectively for the concentrations of $C, B$, and $A+$ $B$ in a reaction of the form $A \rightarrow B \rightarrow C$, governed by first-order rate constants of 0.032 and $0.0026 \mathrm{hr}^{-1}$. In panel $\mathrm{C}$, "relative absorbance" at different wavelengths is plotted against time, with relative absorbance at $\lambda_{\mathrm{nm}}$ defined as $5 \times\left[A_{\lambda}-\left(A_{\lambda-30 \mathrm{~nm}}+A_{\lambda+30 \mathrm{~nm}}\right) / 2\right]$. Plotting in this way is expected to minimize interference from possible baseline shifts or turbidity changes. Vertical markers at the top of panel a indicate the wavelengths at which relative absorbances are plotted in panel c. In panel c, curves through the experimental points (each in duplicate) correspond to a first-order reaction with rate constants, respectively, for 720,630 , and $352 \mathrm{~nm}$, of $0.032 \pm 0.001,0.031 \pm 0.001$ and $0.034 \pm 0.002 \mathrm{hr}^{-1}$. For $430 \mathrm{~nm}$, two successive first-order reactions were assumed with rate constants of 0.032 and $0.0026 \mathrm{hr}^{-1}$. 
These data are interpreted (see below, Scheme 1) in terms of two successive first-order reactions. Loss of activity in the backward assay and of the long-wavelength absorption are associated with the primary reaction $\left(\right.$ reaction $2^{+}$), and activity loss in the forward assay and the small negative relative absorbance change at $430 \mathrm{~nm}$ are associated with the secondary phase (reaction 3). With a first-order rate constant of $0.032 \mathrm{hr}^{-1}$ for the primary reaction, then for the secondary phase, a rate constant of $0.0026 \mathrm{hr}^{-1}$ may be calculated from the forward activity data. In Figure $4 \mathrm{~b}$, curves 3, 4, and 5 correspond, respectively, to plots on the basis of this Scheme for the concentrations of the final product, the primary product, and the sum of the concentrations of this and the starting material (this corresponding to the predicted activity remaining in the forward assay). The same rate constants were used in plotting the curve through the 430-nm data in Figure 4c.

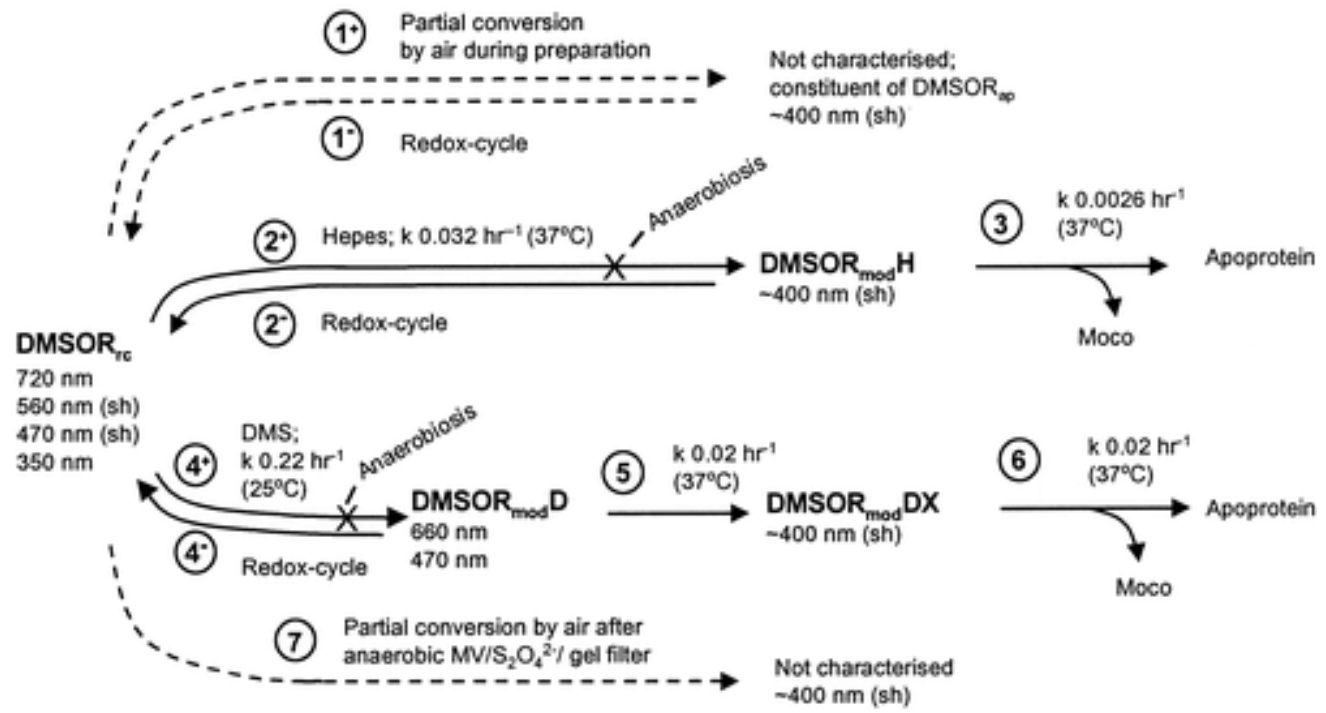

Scheme 1: Proposed Forms of DMSOR and Their Interconversions ${ }^{a}$

${ }^{a}$ The positions of the main absorption peaks and shoulders (sh) are indicated for each species. Forms DMSOR $\mathrm{R}_{\mathrm{rc}}$, $\mathrm{DMSOR}_{\bmod } \mathrm{H}$, and DMSOR $\mathrm{Rod}_{\bmod } \mathrm{D}$ are all fully active in the forward assay but of these, only DMSOR $\mathrm{R}_{\mathrm{rc}}$ is also active in the backward assay. Forms from which Moco has dissociated are inactive. Note that DMSOR ap is proposed to be a mixture of DMSOR ${ }_{\mathrm{rc}}$ together with variable but usually small amounts of the product of reaction $1^{+}$, with sometimes also some $\mathrm{DMSOR}_{\bmod } \mathrm{D}$.

The final product of this experiment was examined further. Although after membrane filtration to remove the $\mathrm{Na}^{+}$-Hepes and transfer of the sample to Tris- $\mathrm{Cl}^{-}$the spectrum retained an extremely high proportion of XS400, nevertheless, the filtration resulted in a significant loss of 400-nm absorption (Supporting Information, Table S1, Figure S1). By analogy with the more definitive data reported below for thermal modification of DMSOR $\mathrm{R}_{\bmod } \mathrm{D}$, it is assumed (Scheme 1) that this loss results from liberation of some Moco from the enzyme (reaction 3 ). In the final spectrum of the gel-filtered product of $\mathrm{Na}^{+}$-Hepes-mediated modification, termed DMSOR $\bmod \mathrm{H}$, after correcting by deconvolution for unreacted $\mathrm{DMSOR}_{\mathrm{rc}}$ and for light scattering, a 400-nm shoulder is the most prominent feature, with additional very weak features at 500 and $680 \mathrm{~nm}$. Upper and lower limits for $\varepsilon_{400 \mathrm{~nm}}$ for DMSOR $\mathrm{mod}_{\mathrm{H}} \mathrm{H}$ were 1.2 and $0.5 \mathrm{mM}^{-1} \mathrm{~cm}^{-1}$.

$\mathrm{DMSOR}_{\bmod } \mathrm{H}$, like DMSOR $\mathrm{R}_{\bmod } \mathrm{D}(\underline{9})$, retained activity in the forward assay and it was therefore of particular interest to test the effect of redox-cycling on it (specifically, on the above gel-filtered sample). This treatment restored in substantial part the $\mathrm{DMSOR}_{\mathrm{rc}}$ spectrum (see Figure 1c). Furthermore, the redox-cycled material was active in both assays. In more detail, our findings are consistent with reaction $2^{+}$of Scheme 1 being very largely reversed by redox cycling (reaction 2') but reaction 3 not being reversed. A significant residue of a species with an XS400-like spectrum is indicated by the fit (Figure 1c and Supporting Information, Table S1). Also, the 
absorbance ratio, $A_{280} / A_{720}=100$, was rather higher than the value of $\sim 80$ reported (9) for $D M S O R_{a p}$ and confirmed for DMSOR $\mathrm{r}_{\mathrm{rc}}$ in the present work. At the end of the $\mathrm{Na}^{+}$-Hepes incubation (but before transfer to Tris$\mathrm{Cl}^{-}$), specific activities as catalytic center activities in the forward and backward assays, respectively [data from Figure $4 \mathrm{~b}$, recalculated relative to $A_{720 \mathrm{~nm}}$ values at the start of the experiment], were 20 and $0.6 \mathrm{~s}^{-1}$. In contrast, for the final redox-cycled material (based on actual $A_{720 \mathrm{~nm}}$ measurements), activities were 22 and $7 \mathrm{~s}^{-1}$, i.e., similar to, but slightly less than, values for normal DMSOR $_{\mathrm{rc}}$ samples.

\section{Basis of the Specificity of Hepes.}

Further investigations were aimed at understanding the remarkable specificity of Hepes, as revealed in the stability experiments. The spectrum of DMSOR was reported ( $\underline{9})$ to be $\mathrm{pH}$-independent, at least over a limited range. However, we found (Supporting Information, Figure S2) that several buffers having sulfonic acid groups in their structures had quite marked effects on the spectrum, in comparison with that recorded in $\mathrm{Tris}_{-} \mathrm{Cl}^{-}$or $\mathrm{Na}^{+}-$ Bicine. These included (in decreasing order of difference spectral amplitude) $\mathrm{Na}^{+}-\mathrm{Ches}, \mathrm{Na}^{+}-\mathrm{Mes}$, and $\mathrm{Na}^{+}-\mathrm{Hepes}$. In the case of $\mathrm{Na}^{+}$-Ches, the observed change included a shift of the long-wavelength peak from 722 to $729 \mathrm{~nm}$. The spectral changes observed, which were reversible on removal of the buffer by gel filtration, are analogous to those for the binding of DMSO $(\underline{9})$ to the enzyme.

The binding site, in the complexes that must be responsible for these spectral changes, has not been determined but a likely site both for DMSO and for the buffer ions is located in the substrate binding channel adjacent to the active site. Such a site would be close enough to molybdenum for binding to cause the minor perturbations of its environment indicated by the spectral changes. Some support for this site is provided by the difference electron density map shown in Figure 5, derived for the structure of the Hepes-modified enzyme. There is evidence for continuous density representing a molecule binding in the substrate-binding channel of the enzyme, between residues Trp 196 and Tyr 165.

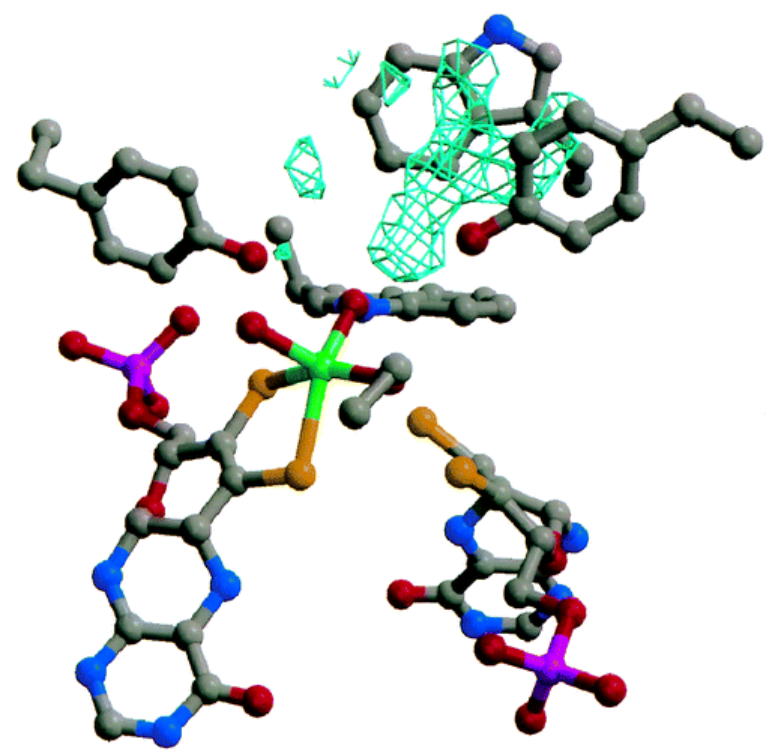

Figure 5 Difference electron density map, contoured at 3.0 $\sigma$, for structure II shown in Figure $2 b$, showing electron density proposed to be due to a disordered Hepes molecule. Similar electron density was seen between Trp 196 and Tyr 165 in structures I and III but not in the structure of oxidized DMSOR crystallized from citrate buffer. The following additional amino acid residues are shown: Try 114, Trp 116, Ser 147 (part). This figure was

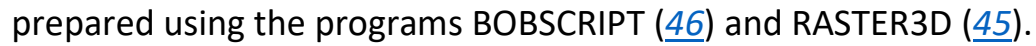


Stability of DMSOR mod $_{\text {D. }}$

We examined the stability of $D M S O R_{\text {mod }} D$ in experiments analogous to those on DMSOR $\mathrm{r}_{\mathrm{rc}}$ In sharp contrast to the situation with the latter, in parallel experiments on $\mathrm{DMSOR}_{\bmod } \mathrm{D}$ in $\mathrm{Na}^{+}$-Hepes and in Tris- $\mathrm{Cl}^{-}$buffers, no significant stability differences were found. Also, $\mathrm{Na}^{+}$-Hepes had virtually no effect on the spectrum of $\mathrm{DMSOR}_{\text {mod }} \mathrm{D}$ at the start of the experiment (data not shown). Data from the stability experiment in Tris- $\mathrm{Cl}^{-}$are summarized in Supporting Information, Figure S3. After 2 days' incubation at $37^{\circ} \mathrm{C}$, the 660 -nm feature of the $\mathrm{DMSOR}_{\bmod } \mathrm{D}$ spectrum had decreased to about half its original intensity, while absorption around $400 \mathrm{~nm}$ had increased. The sample was then submitted to membrane filtration, and the spectra of the filtrate and the retentate were recorded. That of the former, with $\lambda_{\max } \sim 375 \mathrm{~nm}$ and with no $280-\mathrm{nm}$ peak (data not shown), is similar to that of the oxidized molybdenum cofactor liberated from biotin sulfoxide reductase by denaturation $(\underline{35})$ or to that of oxidized carboxamidomethylated MPT (흐). Clearly, some cofactor liberation has taken place. (Note that on a molar basis the oxidized cofactor has a severalfold higher absorption at $375 \mathrm{~nm}$ than does the enzyme). Deconvolution of the spectrum of the retentate was performed analogously to that for the spectrum of $\mathrm{DMSOR}_{\bmod } \mathrm{H}$, as described above, yielding the spectrum of the first product of $D M S O R_{\bmod } \mathrm{D}$ decay, termed $\mathrm{DMSOR}_{\bmod } \mathrm{DX}$. As for DMSOR $\mathrm{mod}_{\mathrm{H}} \mathrm{H}$, a $400-\mathrm{nm}$ shoulder is the most characteristic feature, although a very weak feature at $700 \mathrm{~nm}$ appears also to be real. Rough calculation gives upper and lower limits for $\varepsilon_{400 \mathrm{~nm}}$ of $\mathrm{DMSOR}_{\text {mod }} \mathrm{DX}$ of 5 and $2 \mathrm{mM}^{-1} \mathrm{~cm}^{-1}$ (values considerably higher than the corresponding ones for DMSOR $\mathrm{Rod}_{\mathrm{m}} \mathrm{H}$ ).

The decrease in the concentration of $\mathrm{DMSOR}_{\bmod } \mathrm{D}$ in the above experiment, calculated from deconvolution of the spectrum of the retentate was $56 \%$ (indistinguishable from $54 \%$ found in the parallel experiment in $\mathrm{Na}^{+}$Hepes). If a first-order reaction is assumed, this corresponds to a rate constant of $0.02 \mathrm{hr}^{-1}$ for the conversion of $\mathrm{DMSOR}_{\bmod } \mathrm{D}$ into $\mathrm{DMSOR} \mathrm{R}_{\bmod } \mathrm{DX}$ (Scheme 1, reaction 5). If Moco liberation occurs from the latter by a further firstorder reaction and $\varepsilon_{370 \mathrm{~nm}} 7.34 \mathrm{mM}^{-1} \mathrm{~cm}^{-1}(\underline{37})$ is used to calculate the concentration of oxidized liberated Moco, a rate constant, also of $0.02 \mathrm{hr}^{-1}$, may be calculated for this latter step (Scheme 1, reaction 6).

\section{Reaction of Reduced DMSOR with $\mathrm{O}_{2}$.}

As noted, addition of DMSO is not essential to effective redox cycling of DMSOR samples. To probe this further, an enzyme sample was reduced with $\mathrm{MV}$ and $\mathrm{Na}_{2} \mathrm{~S}_{2} \mathrm{O}_{4}$ and then gel-filtered anaerobically in a glovebox ( $\sim 5 \mathrm{ppm}$ $\mathrm{O}_{2}$ ) to remove the reductants. It then showed the expected spectrum for the reduced enzyme [cf. ref 1; data not shown]. Subsequent exposure of this reduced sample to air gave partial conversion to DMSOR $\mathrm{R}_{\mathrm{rc}}$, accompanied by a substantial increase in the indicated content of an XS400-like spectrum (Supporting Information, Table S1). Thus, for redox-cycling without DMSO to be successful, it seems that the simultaneous presence of reduced enzyme, the reductants, and oxygen is needed. In the absence of the reductants, side reactions between oxygen and the reduced enzyme apparently occur, leading to the formation of additional forms, including ones with increased absorption in the $400 \mathrm{~nm}$ region.

\section{Discussion}

\section{Nature of the Modification of DMSOR Occurring in the Presence of Hepes.}

$\mathrm{DMSOR}_{\text {mod }} \mathrm{H}$ is the primary product of DMSOR modification in the presence of Hepes. Crystallographic data, particularly dataset II of the present study, show that in crystallized DMSOR after extended exposure to Hepes, two thiolate ligands have dissociated from molybdenum. Independent evidence that thiolate ligands can dissociate from the metal under specific conditions involving exposure to Hepes, comes from comparison of the

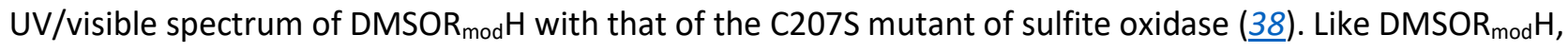
C207S sulfite oxidase has its main long-wavelength absorption feature at about $400 \mathrm{~nm}$, with a molar absorption coefficient [about $1.7 \mathrm{mM}^{-1} \mathrm{~cm}^{-1}$, calculated from refs 38 and 39] comparable to the upper-limit value for $\mathrm{DMSOR}_{\text {mod }} \mathrm{H}$ of $1.2 \mathrm{mM}^{-1} \mathrm{~cm}^{-1}$. According to EXAFS analysis $(\underline{40})$, this sulfite oxidase mutant has three oxo groups 
and two dithiolene sulfur atoms from the single MPT molecule coordinated to molybdenum rather than the structure expected from wild-type sulfite oxidase (41), with the serine hydroxyl coordinated in place of one of the oxos. Nevertheless, this comparison supports the conclusion that the relatively intense long-wavelength absorption of DMSOR $R_{r c}$ depends on there being four dithiolene sulfur atoms coordinated to the molybdenum. Thus, when thiolate ligands are lost, so too are spectral features with $\lambda>\sim 450 \mathrm{~nm}$.

The spectrophotometric and activity data provide further insights into the reactions occurring in the presence of Hepes. With Hepes but not with other buffers tested, the long-wavelength absorption disappears concomitantly with activity in the backward assay, in an oxygen-dependent reaction with clearly-defined kinetics. Though this reaction may be reversed, a slower one that is irreversible follows it. Hence, maximum conversion to the product of the primary reaction, $\mathrm{DMSOR}_{\bmod } \mathrm{H}$, is predicted to occur at $85 \mathrm{~h}$ reaction time at $37^{\circ} \mathrm{C}$, with maximal conversion of $80 \%$ of the enzyme to this form (see Figure $4 \mathrm{~b}$, curve 4 ). While it is thus impossible, for kinetic reasons, to produce $\mathrm{DMSOR}_{\text {mod }} \mathrm{H}$ on its own, it is clearly obtainable without difficulty as the preponderant species.

A number of buffers that we tested bind to the enzyme, but Hepes is unique among them. It alone promotes backward assay activity loss and loss of absorption at $\lambda>\sim 450 \mathrm{~nm}$, both of which we attribute to thiolate dissociation. The difference between Hepes and the other buffers must lie in its chemical structure. Accepting that the buffers that complex with the enzyme bind at a site in the substrate-binding channel, we speculate that Hepes binds in a way such that its $\mathrm{CH}_{2}-\mathrm{CH}_{2}-\mathrm{OH}$ group can coordinate to molybdenum, thereby displacing another ligand, presumably a thiolate, from the metal and so triggering the observed oxygen-mediated decay.

\section{Oxygen-Mediated DMSOR Modification Reactions.}

Information from the present and earlier ( 9 ) work on the various forms of the enzyme and their kinetic interrelationships and spectral properties are summarized in Scheme 1 . Data on reactions $4^{+}$and $4^{-}$are from ref 9; reactions $2^{+}, 2-3,5$, and 6 have been considered in Results. Evidence for oxygen-dependence has been demonstrated where indicated, i.e., for reactions $2^{+}$and $4^{+}$, although it is probably reasonable from analogies with reaction $2^{+}$to assume it applies also to reaction 5 . We have not shown that reaction 6 follows reaction 5 rather than running in parallel with it, but the former is assumed by analogy with reactions $2^{+}$and 3 . We have not attempted to test for reversal, by redox-cycling, of reaction 5 . This might be difficult to demonstrate because of the similarity of the rate constants for reactions 5 and 6 . The remaining reactions are considered below.

As already noted, DMSOR $\bmod \mathrm{D}$ is considered to be an oxygen-damaged DMSOR form. While structural data on this enzyme form are not yet available, the likely structure is pertinent. Adams et al. (ㅁ) speculated that a pair of dithiolene sulfurs might have dissociated from the metal, as we have now shown to be the case in DMSOR $\bmod H$. However, for DMSOR mod $\mathrm{D}$ this is almost certainly incorrect, as is shown by its retention of long-wavelength absorption, at undiminished intensity relative to the native enzyme, although with $\lambda_{\max }$ shifted from 720 to 660 $\mathrm{nm}$. It seems therefore that the structural difference between DMSOR $\mathrm{Rod}^{\mathrm{D}}$ and the native enzyme relates to changes involving oxygen ligation rather than sulfur ligation. In contrast, DMSOR mod $\mathrm{DX}$ has lost long-wavelength absorption, indicating dithiolene sulfur detachment. Thus, we conclude (Scheme 1) that rather than reaction $4^{+}$, reaction 5 , like reaction $2^{+}$, involves dissociation of a pair of dithiolene sulfurs from molybdenum.

\section{Relation between DMSORrc and DMSORap.}

In most of the present work, DMSOR samples submitted to redox-cycling (DMSOR ${ }_{r c}$ ) were used, since these were more consistent in their spectral properties than conventionally prepared ones (DMSOR ${ }_{a p}$ ). The nature of the difference between such samples must be considered. Redox-cycling is known (9; confirmed in the present work) to convert $D M S O R_{\text {mod }} D$ to $D M S O R_{r c}$ and clearly, for some $D M S O R_{a p}$ samples, elimination of contaminating $D_{M S O R} \bmod D$ is one of the effects of this treatment. The occasional presence of some DMSOR $R_{\text {mod }} D$ in 
$\mathrm{DMSOR}_{\text {ap }}$ samples may be explained by variations in the growth conditions, e.g., in the level of anaerobiosis achieved. Other material eliminated by redox-cycling, according to our spectral analyses, absorbs in the 400-nm region, as represented by the synthesized XS400 spectrum. The nature of this material is unsure; it is almost certainly more than one chemical species. Spectral contamination with such material is not unique to our samples. Thus, according to our analysis of the published spectrum, the as-prepared recombinant DMSOR of

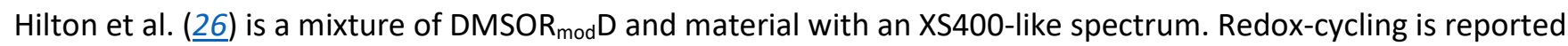
to convert this mixture to normal enzyme. The very substantial contamination by XS400 indicated by the spectrum of these workers must be emphasized. On the plausible assumption that here the 400-nm feature is due to $\mathrm{DMSOR}_{\bmod } \mathrm{DX}$, then a conservative calculation from our molar absorbances indicates that DMSOR $\mathrm{Rod}_{\bmod } \mathrm{D}$ and $\mathrm{DMSOR}_{\text {mod }} \mathrm{DX}$ are present in amounts roughly stiochiometric with one another. This clearly has an important bearing on the interpretation of published EXAFS data (17).

Reverting to Scheme 1, although only limited data have been presented in support of reaction 7, its existence is clear as discussed in Results. Evidence for reaction $1^{+}$is indirect and based on the presumption that DMSOR $_{\mathrm{rc}}$ represents the true native form of the enzyme, with $400 \mathrm{~nm}$-absorbing material in DMSORap resulting from oxygen-mediated degradation reactions, analogous to reactions $2^{+}$and 5 and probably 7 , that have taken place during growth and enzyme isolation. The existence of reaction $1^{-}$is assumed from the effects of redoxcycling on DMSOR ap.

\section{Oxygen-Damaged DMSOR Forms: Structural Implications.}

The new finding that oxygen has harmful effects on DMSOR under some conditions has a profound bearing on the conclusions from structural work. Care is called for in work on the enzyme to ensure that samples studied are free from contamination by oxygen-damaged forms such as those encountered in the present work. Since these lack absorption in the long-wavelength region, their presence could easily remain undetected. In

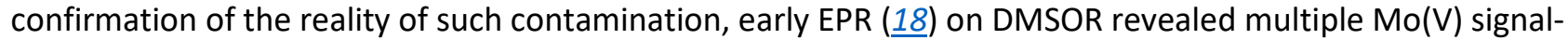
giving species, presumably related to microheterogeneity of the enzyme analogous to that here documented. The existence of oxygen-damaged forms of DMSOR was not known to earlier workers. That the enzyme is under many conditions quite stable in air gives a false sense of security, as does the fact that standard forward assay conditions lead to reversal, by redox-cycling, of any inactivation that may have occurred. We have shown that all known Mo(IV) and Mo(VI) enzyme forms, that is, oxidized, DMS-reacted, and reduced enzyme, are susceptible to this type of damage, although in the case of the first-named form, it is only the complex with $\mathrm{Na}^{+}-\mathrm{Hepes}$ that has clearly been shown to be susceptible. The possibility therefore has seriously to be considered that microheterogeneity of the enzyme due to oxygen damage might explain complexities in published spectroscopic work on this enzyme.

In relation to crystallography, clearly data on DMSOR samples that have been exposed extensively and aerobically to Hepes is not directly relevant to the native enzyme structure. This conclusion is particularly pertinent to the work of Schindelin et al. (13), since these workers crystallized their enzyme in Hepes buffer. It may also be relevant to the work of Butler et al. (21), who performed EXAFS studies in Hepes on another DMSOR family enzyme, periplasmic nitrate reductase. $\underline{5}$ Schneider et al. (14) who reported a DMSOR structure with extensively dissociated thiolate ligands, used Mes not Hepes, a buffer not investigated in relation to enzyme stability in the present work. However, it seems significant that the crystallization conditions of these workers involved one month at $30^{\circ} \mathrm{C}$. Our work on DMSOR mod $\mathrm{D}$ stability shows that the presence of Hepes is not obligatory for the occurrence of damage to the enzyme.

In relation to the structure of DMSOR, potential movement of the molybdenum atom (as described in Results), in a small proportion of the molecules of the sample studied, compromises the assignment of electron density peaks in the coordination sphere of the metal. A $20 \%$ occupied molybdenum atom [ $\mathrm{Mo}^{6+}$ ion with $36 \mathrm{e}^{-}$] would 
be expected to give rise to electron density similar to that of a fully occupied oxygen atom. On the basis of, or extrapolating from, the structures described here and previously published from this laboratory $(\underline{11}, 12)$, it is clear that Oy of Ser 147 and $\mathrm{O} 2$ are ligands to the molybdenum of oxidized DMSOR, both in the physiological enzyme and in the Hepes-modified enzyme. Further, the structure with DMSO bound (11) to the molybdenum strongly implies that $\mathrm{O} 2$ is the oxygen ligand atom transferred during catalysis. The situation for $\mathrm{O} 1$, hydrogenbonded to Tyr 114, is much more confusing and leads us to reassess the presence of this as a ligand in our DMSOR structures. For oxygen-damaged forms of the enzyme where the molybdenum is only coordinated by two thiolates [e.g., structure II, (14)], an oxygen ligand, equivalent to 01, seems the only reasonable interpretation of the metal site. However, for structures of the enzyme with molybdenum coordinated by four thiolate ligands $(11,12)$, an alternative interpretation to 01 being a ligand could be that a small proportion of molybdenum (15-20\%) has moved from its physiological position, giving the appearance in the electron density maps of a spurious additional ligand. Figure 3 shows that the exact position of $\mathrm{O} 1$ depends on the position of the molybdenum atom, but that the molybdenum in Hepes-modified enzyme is very close to the indicated position of $\mathrm{O} 1$ in enzyme with molybdenum coordinated to four thiolates. Thus, it is by no means clear that $\mathrm{O} 1$ is a part of the physiological active site, despite its apparently being present in all crystal structures published to date. Removing 01 from the molybdenum coordination sphere of our previously published structure of oxidized DMSOR (11) would predict a metal site that agrees with spectroscopic data $(16,17,20)$ on DMSOR. Refinement of the molybdenum site with this interpretation has been attempted using the $1.82-\AA$ data on the oxidized enzyme, but a completely satisfactory fit was not achieved (data not shown) and further experiments, at higher resolution, are needed to resolve this controversy.

\section{Significance of the Dissociation of Thiolate Ligands from DMSOR.}

We have shown that thiolate dissociation is a particular form of oxygen damage to which DMSOR is susceptible. Loss by DMSOR mod $_{\text {H }}$ of all activity in the backward assay is of particular significance. This provides the clearest evidence to date that sulfur ligand dissociation, specifically of dissociation of a pair of thiolates, is an artifact and not part of the catalytic cycle. This applies, presumably not only for DMSOR, but also to other members of this enzyme family. In DMSOR $\mathrm{mod}_{\mathrm{H}} \mathrm{H}$, the dissociated thiolates may have linked to form a disulfide, as is implied by the work of Schneider et al. (14). As noted in the introduction, it has been speculated (e.g., 13, 21) that thiolate dissociation might form part of the catalytic cycle of these enzymes. Until now, notwithstanding resonance Raman work $(\underline{16}, 19)$, there has been little direct evidence on the basis of which this postulate might be refuted. Although a variety of mechanisms of thiolate dissociation in DMSOR family enzymes may operate, it seems that all those that are well-established can safely be attributed to oxygen damage.

Ability to transform $\mathrm{DMSOR}_{\mathrm{rc}}$ to $\mathrm{DMSOR}_{\bmod } \mathrm{H}$ and back should facilitate a variety of further spectroscopic studies of the enzyme, e.g., by EPR and Raman spectroscopy. In the latter case, understanding might be advanced of complications (16) concerning transitions related to molybdenum-sulfur bonds. More generally, our findings provide a basis for further work that should soon bring to an end remaining uncertainties concerning the structure and catalytic mechanism of this key member of the DMSOR enzyme family.

\section{Note Added in Proof}

H.-K. Li, C. Temple, K. V. Rajagopalan, and H. Schindelin [J. Am. Chem. Soc. (2000) 32, 7673-7680] very recently published a 1.3-Å resolution structure of DMSOR in which the Mo is discretely disordered, as a mixture of two forms, deduced to be penta- and hexacoordinated. These workers do not report crystallographic studies on the individual enzyme forms nor data on their interconversion in solution or on their spectroscopic or catalytic properties. The nomenclature used for the oxygen ligands to the Mo in the present paper corresponds to that of $\mathrm{Li}$ et al. (2000), in the following manner: $\mathrm{O} 1$ is equivalent $0 x 02$, and $\mathrm{O} 2$ is equivalent oxo1. Clearly, the two forms studied by these workers correspond to structures I and II of the present work. Our suggestion, that 01 
(so numbered in ref 11 and 12 and $\mathrm{H}$-bonded to Tyr 114) might be an artifact of the movement of the Mo, is in agreement with their work. Li et al. (2000) are also in agreement with the earlier result of McAlpine et al. (11) (structure of the enzyme complexed with DMSO), that $\mathrm{O} 2$ (oxo1) is the oxygen atom transferred in catalysis. This oxygen, which is $\mathrm{H}$-bonded to Trp 116, was first detected crystallographically in enzyme having all four thiols ligated, by McAlpine et al. (12).

\section{Supporting Information Available}

Table S1: Deconvolution of the UV/visible spectra of DMSOR samples, as prepared or treated in various ways. Figure S1: UV/visible spectrum of the product of aerobic modification of DMSOR in the presence of $\mathrm{Na}^{+}-\mathrm{Hepes}$. Figure S2: Evidence from UV/visible difference spectra for complex formation between DMSOR and different

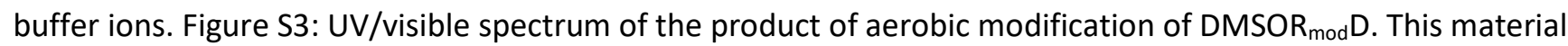
is available free of charge via the Internet at http://pubs.acs.org.

\section{Terms \& Conditions}

Electronic Supporting Information files are available without a subscription to ACS Web Editions. The American Chemical Society holds a copyright ownership interest in any copyrightable Supporting Information. Files available from the ACS website may be downloaded for personal use only. Users are not otherwise permitted to reproduce, republish, redistribute, or sell any Supporting Information from the ACS website, either in whole or in part, in either machine-readable form or any other form without permission from the American Chemical Society. For permission to reproduce, republish and redistribute this material, requesters must process their own requests via the RightsLink permission system. Information about how to use the RightsLink permission system can be found at http://pubs.acs.org/page/copyright/permissions.html.

\section{Acknowledgment}

We are grateful to Dr. A. G. McEwan for providing the $R$. capsulatus strain used for this work and to Mr. S. Reeve for help with the enzyme preparation and for studies of the effects of freezing and thawing.

\section{References}

1 Rajagopalan, K. V., and Johnson, J. L. (1992) J. Biol. Chem. 267, 10199-10202.

2 Schindelin, H., Kisker, C., and Rees, D. C. (1997) J. Biol. Inorg. Chem. 2, 773-781.

3 Hille, R. (1996) Chem. Rev. 96, 2757-2816.

4 Johnson, M. K., Rees, D. C., and Adams, M. W. W. (1996) Chem. Rev. 96, 2817-2839.

5 Kisker, C., Schindelin, H., and Rees, D. C. (1997) Annu. Rev. Biochem. 66, 233-267.

6 Wootton, J. C., Nicolson, R. E., Cock, J. M., Walters, D. E., Burke, J. F., Doyle, W. A., and Bray, R. C. (1991) Biochim. Biophys. Acta 1057, 157-185.

7 Bastian, N. R., Kay, C. J., Barber, M. J., and Rajagopalan, K. V. (1991) J. Biol. Chem. 266, 45-51.

8 McEwan, A. G., Ferguson, S. J., and Jackson, J. B. (1991) Biochem. J. 274, 305-307.

9 Adams, B., Smith, A. T., Bailey, S., McEwan, A. G., and Bray, R. C. (1999) Biochemistry 38, 8501-8511.

10 Czjzek, M., DosSantos, J. P., Pommier, J., Giordano, G., Mejean, V., and Haser, R. (1998) J. Mol. Biol. 284, 435-447.

11 McAlpine, A. S., McEwan, A. G., and Bailey, S. (1998) J. Mol. Biol. 275, 613-623.

12 McAlpine, A. S., McEwan, A. G., Shaw, A. L., and Bailey, S. (1997) J. Biol. Inorg. Chem. 2, 690-701.

13 Schindelin, H., Kisker, C., Hilton, J., Rajagopalan, K. V., and Rees, D. C. (1996) Science 272, 1615-1621.

14 Schneider, F., Lowe, J., Huber, R., Schindelin, H., Kisker, C., and Knablein, J. (1996) J. Mol. Biol. 263, 53-69.

15 Baugh, P. E., Garner, C. D., Charnock, J. M., Collison, D., Davies, E. S., McAlpine, A. S., Bailey, S., Lane, I., Hanson, G. R., and McEwan, A. G. (1997) J. Biol. Inorg. Chem. 2, 634-643. 
16 Garton, S. D., Hilton, J., Oku, H., Crouse, B. R., Rajagopalan, K. V., and Johnson, M. K. (1997) J. Am. Chem. Soc. 119, 12906-12916.

17 George, G. N., Hilton, J., Temple, C., Prince, R. C., and Rajagopalan, K. V. (1999) J. Am. Chem. Soc. 121, 1256-1266.

18 Bennett, B., Benson, N., McEwan, A. G., and Bray, R. C. (1994) Eur. J. Biochem. 225, 321-331.

19 Garton, S. D., Temple, C. A., Dhawan, I. K., Barber, M. J., Rajagopalan, K. V., and Johnson, M. K. (2000) J. Biol. Chem. 275, 6798-6805.

20 George, G. N., Hilton, J., and Rajagopalan, K. V. (1996) J. Am. Chem. Soc. 118, 1113-1117.

21 Butler, C. S., Charnock, J. M., Bennett, B., Sears, H. J., Reilly, A. J., Ferguson, S. J., Garner, C. D., Lowe, D. J., Thomson, A. J., Berks, B. C., and Richardson, D. J. (1999) Biochemistry 38, 9000-9012.

$22 \mathrm{Hu}$, Y., Faham, S., Roy, R., Adams, M. W. W., and Rees, D. C. (1999) J. Mol. Biol. 286, 899-914.

23 Chan, M. K., Markund, S., Kletzin, A., Adams, M. W. W., and Rees, D. C. (1995) Science 267, 1463-1469.

24 Weaver, P. F., Wall, J. D., and Gest, H. (1975) Arch. Microbiol. 105, 207-216.

25 McEwan, A. G., Jackson, J. B., and Ferguson, S. J. (1984) Arch. Microbiol.137, 344-349.

26 Hilton, J. C., Temple, C. A., and Rajagopalan, K. V. (1999) J. Biol. Chem. 274, 8428-8436.

27 Jones, R. W., and Garland, P. B. (1977) Biochem. J. 164, 199-211.

28 Leslie, A. G. W. (1992) Joint CCP4 and ESF-EACMB Newsletter on Protein Crystallography No. 26, CCLRC, Daresbury Laboratory, Warrington, U.K.

29 Collaborative Computational Project No. 4. (1994) Acta Crystallogr.D50, 760-763.

30 Murshudov, G., Vagin, A., and Dodson, E. (1997) Acta Crystallogr. D53, 240-255.

31 Perrakis, A., Sixma, T. K., Wilson, K. S., and Lamzin, V. S. (1997) Acta Crystallogr. D53, 448-455.

32 Jones, A. T., Zou, J.-Y., Cowan, S. W., and Kjeldgaard, M. (1991) Acta Crystallogr. A47, 110-119.

33 Finnegan, M. G., Hilton, J., Rajagopalan, K. V., and Johnson, M. K. (1993) Inorg. Chem.32, 2616-2617.

34 Bastian, N. R., Foster, M. J. P., and Pope, J. C. (1995) BioFactors 5, 5-10.

35 Pollock, V. V., and Barber, M. J. (1997) J. Biol. Chem. 272, 3355-3362.

36 Kramer, A. P., Johnson, J. L., Ribiero, A. A., Millington, D. S., and Rajagopalan, K. V. (1987) J. Biol. Chem. 262, 16357-16363.

37 Johnson, J. L., Bastian, N. R., and Rajagopalan, K. V. (1990) Proc. Natl. Acad. Sci. U.S.A. 87, 3190-3194.

38 Garrett, R. M., and Rajagopalan, K. V. (1996) J. Biol. Chem. 271, 7387-7391.

39 Johnson, J. L., and Rajagopalan, K. V. (1977) J. Biol. Chem. 252, 2017-2025.

40 George, G. N., Garrett, R. M., Prince, R. C., and Rajagopalan, K. V. (1996) J. Am. Chem. Soc. 118, 8588-8592.

41 Kisker, C., Schindelin, H., Pacheco, A., Wehbi, W. A., Garrett, R. M., Rajagopalan, K. V., Enemark, J. H., and Rees, D. C. (1997) Cell 91, 973-983.

42 Dias, J. M., Than, M. E., Humm, A., Huber, R., Bourenkov, G. P., Bartunik, H, D., Bursakov, S., Calvete, J., Caldeira, J., Carneiro, C., Moura, J. J. G., Moura, I., and Romão, M. J. (1999) Struct. Folding Des. 7, 65-79.

43 Dias, J. M., Bursakov, S., Carneiro, C., J, Moura, J. J. G., Moura, I., and Romão, M. J. (1999) Acta Crystallogr. D55, 877-879.

44 Kraulis, P. J. (1991) J. Appl. Cryst. 24, 946-950.

45 Merritt, E. A., and Bacon, D. J. (1997) Methods Enzymol.277, 505-524.

46 Esnouf, R. M. (1997) J. Mol. Graphics15, 132-136.

1 Abbreviations: DMS, dimethyl sulfide; DMSO, dimethyl sulfoxide; DMSOR, dimethylsulfoxide reductase. Variants of the enzyme are $\mathrm{DMSOR}_{\mathrm{ap}}$, oxidized enzyme as purified by the standard procedures here employed (termed "resting" DMSOR in ref 9); $\mathrm{DMSOR}_{\mathrm{rc}}$, enzyme submitted to a cycle of reduction and reoxidation ("redox-cycling"), using prescribed procedures; DMSOR $\bmod D$, modified form prepared by extended aerobic exposure to DMS, having $\lambda_{\max }=660 \mathrm{~nm}$ [previously termed DMSOR $\mathrm{R}_{\bmod }$ (9)]. Other modified forms characterized by absorption at $\sim 400 \mathrm{~nm}$ and a lack of any substantial features at $\lambda>450$ $\mathrm{nm}$ are $\mathrm{DMSOR}_{\text {mod }} \mathrm{H}$, form obtained specifically in the presence of $\mathrm{Na}^{+}$-Hepes; DMSOR mod $\mathrm{DX}$, degradation product of DMSOR mod $D$. Other abbreviations are XS400, name for a synthesized UV/visible spectrum with $\lambda_{\max }=395$ and $\lambda_{\min }=355 \mathrm{~nm}$; PEG, poly(ethylene glycol); MPT, molybdopterin; MGD, 
molybdopterin guanine dinucleotide; Moco, molybdenum cofactor, i.e., for DMSOR, MGD coordinated to Mo; PES, phenazine ethosulfate; DCPIP, 2,6-dichlorophenol-indophenol; MV, methyl viologen; $\mathrm{MV} \bullet$ methyl viologen radical.

2 The authors will endeavor to make the reference UV/visible spectra available in digital form on request by email to r.c.bray@sussex.ac.uk.

$3 \sigma$ is the root-mean-square deviation of the difference electron density map. High values correspond to a significant feature, but absolute values depend on the resolution of the data.

4 There is residual long-wavelength absorption (Figure $4 b$, curve 2 ) after conversion of DMSOR $\mathrm{rc}_{\mathrm{rc}}$ to DMSOR $\mathrm{Rod}_{\bmod } \mathrm{H}$. Although it is virtually free from absorption at $\lambda>\sim 450 \mathrm{~nm}, \mathrm{DMSOR}_{\bmod } \mathrm{H}$ as discussed below retains a very weak feature at about $680 \mathrm{~nm}$ (see Supporting Information, Figure S1).

5 In a recently reported crystallographic structure $(42,43)$ of a periplasmic nitrate reductase, the four sulfur ligand atoms were approximately equidistant from the metal, giving no indications of thiolate dissociation. $\mathrm{Na}^{+}-$Mes was used as the crystallization buffer. However, in comparing buffer effects on different enzymes of the DMSOR family, the nature of the substrate binding site needs to be considered. That of DMSOR is predominantly hydrophobic, with a slight negative charge, whereas the nitrate reductase binding site has a number of charged residues nearby. Thus, the exact nature of small molecules that can affect the molybdenum site is likely to differ for the various enzymes. 